\title{
The Pornography Debate: Religiosity and Support for Censorship
}

Brian A. Droubay

University of Utah

Robert P. Butters

University of Utah

Kevin Shafer

Brigham Young University - Provo, kshafer@byu.edu

Follow this and additional works at: https://scholarsarchive.byu.edu/facpub

Part of the Gender and Sexuality Commons, and the Sociology of Religion Commons

\section{Original Publication Citation}

Droubay, B.A., Butters, R.P. \& Shafer, K. The Pornography Debate: Religiosity and Support for Censorship. J Relig Health (2018).

\section{BYU ScholarsArchive Citation}

Droubay, Brian A.; Butters, Robert P.; and Shafer, Kevin, "The Pornography Debate: Religiosity and Support for Censorship" (2018). Faculty Publications. 4420.

https://scholarsarchive.byu.edu/facpub/4420

This Peer-Reviewed Article is brought to you for free and open access by BYU ScholarsArchive. It has been accepted for inclusion in Faculty Publications by an authorized administrator of BYU ScholarsArchive. For more information, please contact ellen_amatangelo@byu.edu. 


\title{
The Pornography Debate: Religiosity and Support for Censorship
}

\author{
Brian A. Droubay ${ }^{1} \cdot$ Robert P. Butters ${ }^{1} \cdot$ Kevin Shafer $^{2}$ \\ (C) Springer Science+Business Media, LLC, part of Springer Nature 2018
}

\begin{abstract}
Pornography has become an increasingly salient topic in public discourse. We sought to better understand the role of religiosity in shaping people's support of policy stances against pornography, in the form of censorship, using nationally representative data from the 2014 General Social Survey $(n=1676)$. Results from logistic regression indicate that high religiosity significantly increases odds of supporting censorship. Holding control variables at their sample means, the least religious persons had a predicted probability of 0.09 of supporting censorship, compared to 0.57 for the most religious respondents. We discuss these findings within the context of the current public health debate.
\end{abstract}

Keywords Religiosity · Pornography · Censorship · Public health

\section{Introduction}

Spurred by the proliferation of the Internet in the past two decades, access to sexually explicit material and the potential impact of pornography use have become increasingly salient topics in public discourse and policy debates. While conventional wisdom suggests pornography consumption has dramatically increased given greater accessibility, affordability, and anonymity via the Internet (Cooper 1998), recent literature suggests the percentage of adults who view pornography has only increased marginally over the past four decades (Price et al. 2016; Wright 2013), with moderate increases in viewership among young adults - the age group arguably most affected by Internet pornography-compared to past generations of young people (Price et al. 2016). Less clear is whether frequency and duration of use have substantially increased. Additionally, while attitudes about pornography's legality have shifted some, with fewer adults endorsing that pornography should be illegal, young adults' views have largely stayed static over the past four decades (Price et al. 2016).

Brian A. Droubay

brian.droubay@utah.edu

1 College of Social Work, University of Utah, 395 South 1500 East \#111, Salt Lake City, UT 84112, USA

2 Department of Sociology, Brigham Young University, Provo, UT, USA 
Regardless, governmental and political bodies have gone so far as to declare pornography a public health issue. Likening pornography to illicit drugs and citing concerns about deleterious effects, Utah was the first state to pass a resolution (Utah S. Con. Res. 9 2016) declaring pornography a public health crisis, with several other states similarly considering or passing like measures since, including Virginia (Va. H. J. Res. 549 2017), South Dakota (S.D. S. Con. Res. 4 2017), Arkansas (Ark. H. Res. 1042 2017), Tennessee (Tenn. S. J. Res. 35 2017), Kansas (Kan. H. Res. 6016 2017), and Florida (Fla. H. Res. 157 2018). Likewise, the Republican National Committee (2017) added to their platform that pornography is a public health crisis. These resolutions have not been without controversy in the public and media (e.g., Stack 2016).

Further, pornography has recently been a hotly debated topic among academics and mental health professionals. Many researchers and clinicians have argued that sexual behaviors, including pornography viewing, have the propensity to be addictive (e.g., Carnes 1983; Griffiths 2012). Despite this, neither pornography addiction nor hypersexuality more broadly is a recognized diagnosis. Kafka (2010), among others, argued that hypersexual disorder be included in the DSM-5, with a pornography specifier. Ultimately, inclusion was met with resistance (e.g., Halpern 2011; Moser 2011; Wakefield 2012), and it was left out. Kor et al. (2013) note that while viewing hypersexual behavior through an addiction framework might be helpful, given that related research is in its infancy, it is premature to classify it as an addiction at this time. This debate has recently received renewed focus with compulsive sexual behavior disorder receiving consideration for inclusion as an impulse control disorder in the ICD-11 (Kraus et al. 2018).

Antipornography campaigns have, further, gained attention. One the most prominent, Fight the New Drug, advocates (as the name suggests) that pornography is addictive like a chemical substance. They warn that pornography harms the brain, relationships, and society while marketing merchandise and printing billboards with slogans such as "Porn Kills Love" (Fight the New Drug 2017; Zouves 2015). And they have been given a platform in public schools (e.g., Carroll 2015). This, along with their purporting scientific backing, has not been without controversy among some mental health professionals and researchers (Parker et al. 2016; Prause et al. 2016).

This public debate raises the following questions: What informs persons' opinions about pornography? What influences persons' likelihood of supporting policy stances against pornography? And what role do values and religion play? Perhaps the strongest statement of public action against pornography is censorship. Clarkson and Kopaczewski (2013) argue that "placing pornography within the addiction model," as many antipornography advocates do, is a strategy by those "who would seek wide-scale censorship" (p. 128). They further note, "For these mostly conservative advocates, proving that pornography has negative physiological effects on the body effectively neutralizes any argument about censorship or free speech and provides an opportunity to gain ground in the moralist battle against pornography" (p. 128). While none of the above resolutions or campaign groups have overtly advocated for wide-scale censorship of sexually explicit materials, endorsement of antipornography movements is correlated with support of censorship (Fisher et al. 1994). As Lambe (2004) points out, "To influence public attitudes about... pornography (in either direction), one must understand the characteristics of people who do and do not wish to censor such expression" (p. 279).

Of special interest is the relationship between religiosity and support for pornography censorship. Views on sexuality are informed by a myriad of factors, but cultural norms and religious views are particularly influential (Lefkowitz et al. 2004; Sümer 2015). Unsurprisingly, highly religious persons are more likely to have negative attitudes about 
pornography (Lottes et al. 1993; Sümer 2015), less apt to believe viewing it is an acceptable means of expressing one's sexuality (Carroll et al. 2008), and less likely to consume it (e.g., Carroll et al. 2008; Short et al. 2015). It is plausible, then, that religious persons are more apt to pathologize pornography use because they morally disagree with it, and such pathologizing may foster support of censorship.

\section{Literature on Pornography Censorship}

Identifying individual characteristics of persons who support censorship has historically been difficult (Lambe 2004). This is especially true of pornography because divergent groups may support censorship of sexually explicit materials. Moralists and conservatives may be more likely to support censorship because of traditional attitudes about sex and concern about moral decline. On the other hand, some feminists and liberals may support censorship because of opposition to the objectification of women and potential exploitation of vulnerable persons by the pornography industry (Lambe 2004; Linz and Malamuth 1993).

It is apparent that individual characteristics predicting support for censorship differ across mediums. Fisher et al. (1994), for instance, found that attributes correlated with support for censorship of violent media versus sexually explicit media are "clearly distinguishable" (p. 237). Congruently, Hense and Wright (1992) found two distinct factors while developing a scale for censorship — one factor that "dealt with general issues related to freedom of speech and a variety of censorship issues" and the other "which addressed obscenity and sexual explicitness" (p. 1670)—suggesting persons who support pornography censorship may differ from persons who support other forms of censorship. What, then, does past literature say about predictors of support for pornography censorship?

Gender, authoritarian attitudes, and religiosity have dependably correlated with support of pornography censorship. Women are consistently more likely to voice support for pornography censorship than men (Cowan 1992; Fisher et al. 1994; Gunther 1995; Hense and Wright 1992; Lambe 2004; Rojas et al. 1996; Zhao and Cai 2008). Individuals with authoritarian attitudes are more likely to support government restriction of pornography (Fisher et al. 1994; Hense and Wright 1992; Lambe 2004). And persons who are highly religious are more likely to support censorship than less religious persons (Fisher et al. 1994; Lambe 2004; Rojas et al. 1996), though the magnitude of the impact of religiosity is less clear.

Other variables - age, education, and political ideology - have shown mixed results across studies. Fisher et al. (1994), Lambe (2004), Price et al. (2016), and Rojas et al. (1996) found older age to be associated with support of pornography restriction, while Cowan (1992) and Gunther (1995) did not. Results have also varied between studies on educational attainment and socioeconomic background, with some authors finding that less education is correlated with support for pornography censorship (Gunther 1995; Herrman and Bordner 1983), while others have found no relationship (Hense and Wright 1992; Lambe 2004; Rojas et al. 1996). Likewise, while some research has suggested conservatives are more likely to support pornography censorship (Rojas et al. 1996), others have found no significant relationship with political ideology (Lambe 2004; Thompson et al. 1990). 


\section{Aims and Objectives}

The primary aim of the present study was to better understand individual attributes that predict support for pornography censorship, with particular attention given to the impact of religiosity. Notably, we were interested only in persons' attitudes about pornography censorship to adults; we assumed there would be broad consensus that pornography should be censored to minors (which our findings validate below). There is a dearth of literature specific to censorship in the last decade, and this issue is worth revisiting given the current tenor of public discourse. Furthermore, previous studies on pornography censorship have not utilized nationally representative data, so generalizability of past results has always been uncertain.

Given the past literature, it is hypothesized that, controlling for other variables, female gender, authoritarian attitudes, and high religiosity will each significantly predict support for pornography censorship. The relationship between support for censorship and age, education, and political ideology will further be explored, as past research has suggested a possible - but unclear-relationship between these variables. Pornography viewership and whether the participant has children in the household will serve as exploratory variables. And finally, in order to better understand the association between religiosity and support for pornography censorship, we will explore whether gender, authoritarian attitudes, age, or political ideology moderates the relationship between the two.

\section{Methods}

\section{Participants and Procedure}

Data were drawn from the General Social Survey (GSS), which originated in 1972 and "gathers data on contemporary American society in order to monitor and explain trends and constants in attitudes, behaviors, and attributes." (National Opinion Research Center [NORC] 2016). The GSS incorporates a full-probability, repeated cross-sectional design that is representative of English- and Spanish-speaking non-institutionalized US adults. The survey is conducted via in-person interviews; since 1994, the GSS has been administered biennially (see also National Science Foundation 2007).

This study used data from the 2014 GSS, which had an overall response rate of $69 \%$. Not all questions on the GSS are asked of all respondents, however. To increase number of questions asked and topic coverage, the GSS uses a split-ballot design, meaning three random subsamples are created from the overall sample and questions are rotated depending on the ballot (for a detailed explanation, see NORC 2016). Each of the subsamples is also representative. The outcome variable and predictors for this study were included on two of the three ballots. Thus, the sample is comprised of $65 \%$ of all GSS respondents for year 2014. The total sample consists of 1687 persons (while the overall GSS had 2583 participants in 2014). Eleven persons were missing data on the outcome variable $(0.7 \%)$, so those cases were deleted listwise $(n=1676)$. 


\section{Measures}

\section{Pornography Censorship to Adults}

The outcome variable of interest is support for pornography censorship. This was assessed via the following question on the GSS: "Which of these statements comes closest to your feelings about pornography laws?" Response options include illegal to all, illegal under 18, and legal. Unsurprisingly, very few participants answered legal (4\%), meaning the vast majority of respondents at least support pornography censorship for minors (as we predicted). Because of this, response options illegal under 18 and legal were collapsed into one category, representing non-censorship to adults, while illegal to all represents censorship to adults.

\section{Religiosity}

Past measurement strategies for religiosity have included assessing persons' behaviors, beliefs, and sense of belonging within a faith (Mockabee et al. 2001). The GSS includes several questions on religion that tap into each of these areas. Seven items were utilized to create a scale of religiosity. The items inquired about respondents' frequency of (1) religious service attendance, (2) prayer, and (3) participation in religious activities outside of worship services; respondents' (4) confidence in the existence of God; respondents' (5) self-reported strength of religious affiliation; and, finally, to what degree respondents consider themselves a (6) religious or (7) spiritual person. Because the number of response options for each of the items varied (ranging from 4 to 10), all responses were transformed to a 10 -point scale.

A principle axis factor (PAF) analysis was conducted on these items. The KaiserMeyer-Olkin measure suggested sampling adequacy $(\mathrm{KMO}=0.87)$, and KMO values for individual items all exceeded 0.83 , which is greater than the minimum acceptable limit of 0.5 (Field 2013). To determine the optimal number of factors to extract, we examined several criteria: the Kaiser-Guttman criterion (Guttman 1954; Kaiser 1960), the scree test (Cattell 1966), parallel analysis (Horn 1965), and the minimum average partial test (Velicer 1976). Taken together, these analyses strongly pointed to retaining only 1 factor, suggesting a unidimensional structure to the scale. The factor loadings for the above seven items were $0.78,0.77,0.63,0.68,0.76,0.80$, and 0.65 , respectively. The scale also exhibited high internal consistency $(\alpha=0.89)$. A single religiosity score was then created for each respondent by summing their item scores; thus, religiosity scores ranged from 7 (non-religious) to 70 (extremely religious).

\section{Authoritarianism}

Authoritarianism was measured via one question on the GSS that asks respondents to rank (from 1 to 5) how important it is for children to learn obedience in preparing them for life. While these two ballots of the 2014 GSS did not contain other questions appropriate to measuring authoritarianism, a very similar item was included on the original F-scale (Adorno et al. 1950), as well as the Right-Wing Authoritarian Scale (Altemeyer 1981), and has been included on subsequent measures of authoritarianism (e.g., Rattazzi et al. 2007). 


\section{Gender, Political Ideology, Education, and Age}

Gender was dummy coded so $0=$ male and $1=$ female. Political ideology was assessed via a question that asks participants to place themselves on a seven-point political scale ranging from 1 (extremely liberal) to 7 (extremely conservative). Education was measured via highest degree attained; responses were dummy coded and ranged from 0 (less than high school) to 4 (completion of a graduate degree). And age was entered into the model as continuous variable.

\section{Control Variables}

Race/ethnicity, religious affiliation, and income were included as control variables. Race/ ethnicity was coded so that $0=$ White, $1=$ Hispanic, $2=$ Black, and $3=$ other. The GSS solicits information about religious affiliation via the following question: "What is your religious preference? Is it Protestant, Catholic, Jewish, some other religion, or no religion?" Follow-up questions are then asked depending on the response given. By far, the most common response given in the current sample was Protestant (44\%). Unfortunately, this a very broad and likely indiscriminate category, so religious affiliation was recoded and categorized based on Steensland et al.'s (2000) findings and recommendations, except that persons answering Jewish were included in the other category due to insufficient sample size. Thus, religious affiliation is coded as follows: $0=$ none, $1=$ Roman Catholic, $2=$ Mainline Protestant, $3=$ Black Protestant, $4=$ Evangelical Protestant, and $5=$ other (e.g., Jewish, Hindu, Muslim, Jehovah's Witness, Mormon, etc.).

Household income was measured via the following question on the GSS: "In which of these groups did your total family income, from all sources, fall last year, before taxes, that is." Response options include categories ranging from under $\$ 1000$ to over $\$ 150,000$. These were recoded as follows: $0=$ under $\$ 25,000, \quad 1=\$ 25,000-49,999$, $2=\$ 50,000-74,999,3=\$ 75,000-109,999,4=\$ 110,000-149,999$, and $5=\$ 150,000$ plus.

\section{Exploratory Variables}

Other variables were included in the model for exploratory purposes. The GSS includes a question about household type, which incorporates many categories (e.g., single adult, no children; single adult with children; married couple, no children, etc.). These categories were recoded into a binary variable where $0=$ no children in the household and $1=$ children in the household (regardless of the rest of the household makeup). Given that much of the rhetoric surrounding public health and pornography revolves around protecting children — and given that the overwhelming majority of adults in the present sample favor censoring pornography for minors - this seemed like a variable of interest.

Another relevant variable is pornography viewership. It seems probable that those who actively consume pornography are less likely to oppose censoring it. Pornography consumption was measured via the following question on the GSS: "Have you seen an X-rated movie in the last year?" Responses were dummy coded $0=$ no and $1=$ yes. Given that the term "X-rated movie" is somewhat antiquated, it raises questions as to whether this item adequately measures pornography consumption. Would young adults who visit pornographic sites and watch sexually explicit clips online, for instance, endorse having watched an X-rated movie? Price et al. (2016) utilized previous waves of the GSS (years 2000 to 
2004) that included the above X-rated movie item along with a question inquiring whether respondents had visited a pornographic website (not included on the 2014 GSS) and compared responses of participants who answered both questions. They noted when respondents endorsed one question, they frequently endorsed the other and concluded that "the Internet has not dramatically altered the way young adults report whether they have watched an X-rated movie" (p. 14), suggesting this item is an adequate measurement for pornography consumption.

\section{Analysis}

All analyses were conducted using IBM SPSS Statistics 24. Before the main analysis, missing data were examined. (As noted prior, cases with missing data on the outcome variable were deleted listwise beforehand.) Only $1.20 \%$ of all values were missing, though $15 \%$ of the cases had at least one missing value. Little's (1988) test was significant $(p<0.001)$, suggesting the data were not missing completely at random (MCAR). Subsequent tests of group difference revealed that missingness in the variables of interest was significantly associated with other measured variables in the model, suggesting the data were missing at random (MAR). Consequently, multiple imputation procedures were used. A total of 20 imputations were run.

Univariate statistics were used to describe the sample and study variables. For the main analysis, hierarchical logistic regression was utilized to examine the relationship among predictor variables and the outcome variable. The first block included variables past literature has suggested are consistently associated with support for pornography censorship: religiosity, attitudes of authoritarianism, and gender. The second block incorporated variables past literature has suggested may be associated with support for pornography censorship: political ideology, educational status, and age. The third block included control variables - race, religious affiliation, and income-as well as the two exploratory variables: children in household and pornography consumption. This analytic strategy was chosen based on Field's (2013) recommendation to enter "known predictors" into the model first (p. 322), which subsequently provides clarity as to which block is most parsimonious and whether exploratory variables are significantly fostering model improvement.

And finally, because the relationship between religiosity and support for pornography censorship was a specific focus of this study, interaction effects were also explored. More specifically, we explored whether gender, authoritarian attitudes, age, or political ideology moderated the relationship between religiosity and the outcome variable. These particular variables were selected as moderators based on past literature suggesting their relationship with the outcome variable (see above). Additional logistic regression models were run for each of these interaction terms (i.e., gender*religiosity, authoritarian attitudes*religiosity, age*religiosity, political ideology*religiosity) separately, controlling for the same covariates as in block 3 described above.

\section{Results}

Descriptive statistics for the sample and key covariates are provided in Table 1. The majority of respondents identified as White $(75 \%)$, with a mean age of $49.0(S D=17.3)$. Women made up a small majority (55\%) of the sample. The most common level of educational attainment was high school (51\%), while the most common religious group 
Table 1 Descriptive characteristics of the variables and sample $(N=1676)$

\begin{tabular}{|c|c|c|c|}
\hline & $M \pm S D$ & Range & $\%$ \\
\hline \multicolumn{4}{|l|}{ Pornography censorship } \\
\hline No & & & 66.4 \\
\hline Yes & & & 33.6 \\
\hline Religiosity & $40.3 \pm 16.2$ & $7-70$ & \\
\hline \multicolumn{4}{|l|}{ Sex } \\
\hline Male & & & 44.7 \\
\hline Female & & & 55.3 \\
\hline Authoritarianism & $2.6 \pm 1.3$ & $1-5$ & \\
\hline Political ideology & $4.1 \pm 1.4$ & $1-7$ & \\
\hline \multicolumn{4}{|l|}{ Education } \\
\hline Less than high school & & & 13.2 \\
\hline High school & & & 50.7 \\
\hline Junior college & & & 7.0 \\
\hline Bachelor's degree & & & 18.3 \\
\hline Graduate degree & & & 10.9 \\
\hline
\end{tabular}

Age

$49.0 \pm 17.3$

$18-89$

Race/ethnicity

White

Hispanic

Black

Other

Religious affiliation

None

Catholic

Mainline Protestant

Black Protestant

Evangelical Protestant 28.6

Other

Income

Under $\$ 25,000$

$\$ 25,000-49,999$

$\$ 50,000-74,999$

$\$ 75,000-109,999$

\$110,000-149,999

$\$ 150,000$ plus

Children in household

No

Yes

Pornography consumer

No

Yes 
was Evangelical Protestant (29\%), followed by Catholic (25\%). As can be seen, respondents opposed censorship of pornography for adults two-to-one $(66 \%)$.

Results from the hierarchical logistic regression are presented in Table 2 . The omnibus results for each block were compared (i.e., $\chi^{2}=\chi_{\text {block2 }}^{2}-\chi_{\text {block } 1}^{2} ; \chi^{2}=\chi_{\text {block3 }}^{2}-\chi_{\text {block2 }}^{2}$ ) to assess model improvement. Each successive block significantly improved overall model fit

Table 2 Hierarchical logistic regression of support for pornography censorship

\begin{tabular}{|c|c|c|c|c|c|c|}
\hline \multirow[t]{2}{*}{ Variable } & \multicolumn{2}{|l|}{ Step 1} & \multicolumn{2}{|l|}{ Step 2} & \multicolumn{2}{|l|}{ Step 3} \\
\hline & $b(\mathrm{SE})$ & $\begin{array}{l}\text { Odds } \\
\text { ratio }\end{array}$ & $b(\mathrm{SE})$ & $\begin{array}{l}\text { Odds } \\
\text { ratio }\end{array}$ & $b(\mathrm{SE})$ & $\begin{array}{l}\text { Odds } \\
\text { ratio }\end{array}$ \\
\hline \multicolumn{7}{|l|}{ Step 1} \\
\hline Religiosity & $\begin{array}{l}0.05 \\
\quad(0.00)^{* * * *}\end{array}$ & 1.05 & $0.04(0.00)^{* * *}$ & 1.04 & $0.04(0.01)^{* * *}$ & 1.04 \\
\hline Sex & $\begin{array}{l}0.78 \\
\quad(0.12) * * *\end{array}$ & 2.18 & $0.83(0.12)^{* * *}$ & 2.29 & $0.74(0.13)^{* * *}$ & 2.09 \\
\hline Authoritarianism & $\begin{array}{l}0.23 \\
\quad(0.05)^{* * * *}\end{array}$ & 1.26 & $0.19(0.05)^{* * *}$ & 1.21 & $0.18(0.05)^{* *}$ & 1.20 \\
\hline \multicolumn{7}{|l|}{ Step 2} \\
\hline Political ideology & & & $0.14(0.05)^{* *}$ & 1.15 & $0.11(0.05)^{*}$ & 1.12 \\
\hline \multicolumn{7}{|l|}{$\begin{array}{l}\text { Degree earned } \\
\quad(\text { none })\end{array}$} \\
\hline High school & & & $-0.41(0.17)^{*}$ & 0.66 & $-0.25(0.18)$ & 0.78 \\
\hline Junior college & & & $-0.47(0.27)$ & 0.63 & $-0.32(0.29)$ & 0.73 \\
\hline Bachelor degree & & & $-0.64(0.21)^{* *}$ & 0.53 & $-0.44(0.24)$ & 0.64 \\
\hline Graduate degree & & & $-0.54(0.25)^{*}$ & 0.58 & $-0.31(0.28)$ & 0.73 \\
\hline Age & & & $0.02(0.00)^{* * *}$ & 1.02 & $0.02(0.00)^{* * *}$ & 1.02 \\
\hline \multicolumn{7}{|l|}{ Step $3^{\mathrm{a}}$} \\
\hline \multicolumn{7}{|l|}{$\begin{array}{l}\text { Race/ethnicity } \\
\text { (White) }\end{array}$} \\
\hline Hispanic & & & & & $0.41(0.28)$ & 1.51 \\
\hline Black & & & & & $-0.46(0.23)^{*}$ & 0.63 \\
\hline Other & & & & & $0.32(0.28)$ & 1.38 \\
\hline \multicolumn{7}{|l|}{$\begin{array}{l}\text { Religious affiliation } \\
\text { (none) }\end{array}$} \\
\hline Catholic & & & & & $-0.09(0.23)$ & 0.92 \\
\hline $\begin{array}{l}\text { Mainline } \\
\text { Protestant }\end{array}$ & & & & & $-0.37(0.27)$ & 0.69 \\
\hline Black Protestant & & & & & $-0.24(0.36)$ & 0.79 \\
\hline $\begin{array}{r}\text { Evangelical } \\
\text { Protestant }\end{array}$ & & & & & $0.07(0.24)$ & 1.08 \\
\hline Other & & & & & $0.16(0.29)$ & 1.18 \\
\hline $\begin{array}{l}\text { Children in } \\
\text { household }\end{array}$ & & & & & $0.16(0.15)$ & 1.18 \\
\hline Pornography use & & & & & $-0.90(0.18)^{* * *}$ & 0.41 \\
\hline
\end{tabular}

$S E=$ standard error. Final $R^{2}=0.32$ (Nagelkerke)

$* p<0.05 ; * * p<0.01 ; * * p<0.001$

${ }^{a}$ Household income, a nonsignificant control variable, is omitted from the table 
$(p<0.001)$, apart from the addition of the interaction terms, which did not improve the model. Block 3 produced an $R^{2}$ of 0.32 (Nagelkerke).

As hypothesized, all beta-coefficients for variables entered into the first block were significant $(p<0.001)$. A one-unit increase in religiosity and authoritarianism was associated with persons being 1.05 and 1.26 times more likely of supporting censorship, respectively. (The former is especially notable given that the religiosity scale included 64 units.) Women were 2.18 times more likely to support censorship than men. Notably, the association between all of these predictors and the outcome variable stayed significant for subsequent blocks (2 and 3 ) of the regression.

In block 2 , both political ideology $(b=0.14, p<0.01)$ and age $(b=0.02, p<0.001)$ were significantly associated with the outcome variable. In sum, as conservatism and age increase, the odds of supporting pornography censorship increase. The association between these predictors and the outcome variable also remained significant for block 3. Degree holders of all levels (high school through graduate school) were significantly less apt to support pornography censorship than persons who did not complete high school, excepting the beta-coefficient for junior college, which was not significant $(b=-0.05, p=0.09)$. Notably, however, none of the dummy codes for degree attainment remained significant in block 3 .

For block 3, neither household income (which is excluded from the table) nor religious affiliation was significantly associated with the outcome variable. Regarding the latter, this suggests that strength of religiosity is more important than actual religious affiliation in predicting support for pornography censorship, at least among the Western, Christian faith traditions highlighted in this sample. This notion is further supported via a post hoc moderation analysis (religious affiliation*religiosity), which revealed nonsignificant interaction effects between the two.

Interestingly, for the control variable race, Black persons were significantly less likely $(b=0.46, p<0.05)$ to support censorship than Whites. White individuals were 1.59 (1/ 0.63 ) times more likely to support censorship than Black individuals. Regarding the exploratory variables, having children in the household was not significantly related to the outcome variable, while pornography consumption, as expected, was. Persons who denied having viewed an $\mathrm{X}$-rated movie in the past year were 2.44 times more likely $(1 / 0.41)$ to support censorship $(p<0.001)$.

None of the aforementioned interaction terms produced significant results-gender*religiosity $(b=-0.01, p=0.21)$, authoritarian attitudes*religiosity $(b=0.00$, $p=0.93)$, age*religiosity $(b=0.00, p=0.53)$, political ideology*religiosity $(b=-0.00$, $p=0.68$ ) — suggesting none of the variables of interest moderate the relationship between religiosity and support for pornography censorship and that the relationship between the two is robust regardless of these key individual characteristics. To better conceptualize this relationship, we computed the predicted probabilities of support for censorship at different values of religiosity while holding all other predictors at their sample means (i.e., the sample averages method described in Pollock 2012). Results can be seen in Fig. 1. Taking religious extremes, an "average" respondent with a minimum religiosity score of 7 has a predicted probability of 0.09 of supporting censorship, while an "average" respondent with a maximum religiosity score of 70 has a predicted probability of 0.57 of supporting censorship; thus, spanning its range of values, religiosity increases the probability of censorship support by 0.48 . 


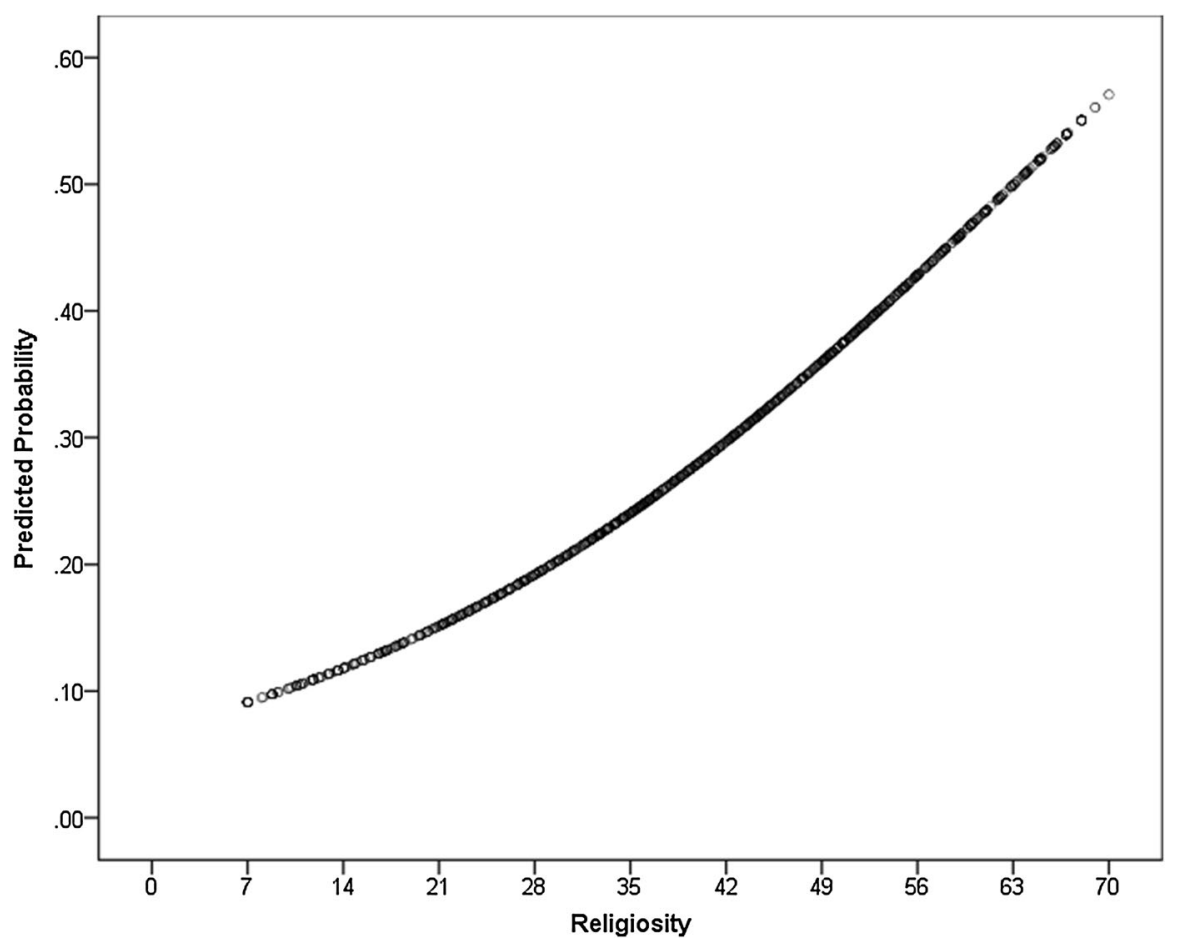

Fig. 1 Scatter plot of predicted probabilities of support for pornography censorship at different values of religiosity, with all other predictors in block 3 held at their sample means

\section{Discussion}

Results from this study bolster findings from previous literature and add insight into the impact of religiosity on people's support for censorship. High religiosity, female gender, authoritarian attitudes, older age, and conservative political ideology are all individual characteristics associated with support for pornography censorship. Regarding the exploratory variables, although much of the public debate surrounding pornography has centered on protecting children, having children in the home does not appear significantly associated with support (or nonsupport) of censorship to adults. Pornography viewership, however, does; persons who view pornography appear less likely to support censorship. Findings on these exploratory variables are consistent with Gunther's (1995) results over two decades ago.

\section{Limitations, Implications, and Direction for Future Research}

The primary limitations of this study are related to using a secondary dataset. Other variables-e.g., sexual conservatism, sex-role stereotyping, and commitment to democratic principles and free speech-have also been shown to correlate with support for pornography censorship (e.g., Cowan 1992; Fisher et al. 1994; Gunther 1995; Lambe 2004). Inclusion of these variables may have improved overall model fit, but they were not measured on these ballots of the 2014 GSS. The GSS question from which the outcome 
variable, pornography censorship, was derived is straightforward but lacks nuance. People likely have nuanced opinions about when and where pornography should be illegal (e.g., television versus the Internet versus supermarket aisles). The question, as is, fails to capture these distinctions. Furthermore, pornography was never explicitly defined in the survey. Individuals from different backgrounds likely have differing interpretations of what constitutes pornography. And finally, people are likely to support censorship for certain types of pornography (e.g., child pornography, violent pornography) more than others (e.g., consensual adult pornography). The question, as is, leaves much up to the interpretation of the participants and forces them into a dichotomous answer, which has its advantages and disadvantages.

Related to this, future research might take a more in-depth, qualitative approach to illuminate the beliefs and reasons persons have for supporting (or not supporting) censorship and other policy initiatives against pornography. Regarding religiosity, a phenomenological approach that explores people's perceptions of pornography and lived experiences with it, for good and bad, would be especially valuable; such an approach would provide greater profundity and nuance. Additionally, given that age is significantly correlated with support for censorship, a longitudinal study may clarify how and why attitudes change over time. A longitudinal design would also provide greater insight into directionality of these relationships; as is, no inferences about directionality can be made given the cross-sectional nature of the data.

\section{The Public Health Debate}

We chose to frame the censorship question within the context of the current public health debate both because of its present salience and because prior data suggest support for antipornography campaigns is significantly related to support of censorship (Fisher et al. 1994). Hence, better understanding who supports censorship may illuminate who is likely to support related policy initiatives. That said, support for censorship is not synonymous with support for these public health declarations. Certain people may support one or the other to varying degrees. As noted prior, divergent groups (e.g., moralists, conservatives, feminists, and liberals) may support pornography censorship for different reasons, and this may also be the case for the public health movement. It may be that those who support censorship for religious or moral reasons view the public health debate differently than those who support censorship strictly out of concern for pornography's impact on women. More research is needed on moderators (e.g., political ideology, religiosity, authoritarianism, attitudes toward feminism) of the relationship between support for censorship and these public health declarations.

Regarding religiosity, recent literature offers clues as to why religious persons are more likely to support strong policy stances, like censorship, against pornography. Grubbs et al. (2015) found, for example, that religiosity, mediated through moral disapproval of pornography, is predictive of perception of addiction to it: that is, highly religious individuals are more likely to perceive they have an addiction to pornography, even when frequency of use is controlled for. Further, spousal religiosity exacerbates the adverse effects of pornography consumption on marital satisfaction (Perry 2016). This suggests that religious persons may not merely want to legislate against what they morally disagree with; rather, they may experience pornography as more destructive personally and familiarly than their non-religious peers, which may explain why they are more likely to support 
strong policy initiatives against it. This is in line with Perry's (2016) contention that the social and psychic costs of pornography consumption are greater in religious households.

Fisher et al. (2018) suggest that policymakers may also be swayed by personal mores in crafting legislation pertaining to pornography: "Political figures weighing in on pornography may possess moral reservations about pornography use by others that can only be balanced by expectations of pornography-induced harm and by supporting an entrenched narrative concerning pornography-induced damage to individuals and society" (p. 3). Ideally, policymaking regarding sexually explicit materials-whether addressing pornography censorship or public health—should be informed by the best available research, encompassing its full breadth rather than cherry-picking studies to fit a moral narrative. The language in the Utah resolution, for instance, speaks authoritatively of "biological addiction" to pornography leading to "extreme degradation, violence, and child sexual abuse images and child pornography" (Utah S. Con. Res. 9 2016). The resolution appears to conflate all types of pornography, overstates findings, and lacks the nuance (of the effects of pornography) found in the literature.

Importantly, the tone of public dialogue and policy debates may inform-or at least reinforce-religious persons' perceptions of pornography's effects. If religious persons are already more likely to perceive they are addicted to pornography, then they may be especially sensitive to hyperbolic messaging of legislative edicts declaring pornography a public health crisis. Thus, there may be a reinforcing cycle wherein religious persons are both more likely to support policy initiatives against pornography and are simultaneously more affected by the messaging of such initiatives. More research is needed in this regard. It is critical that policymakers be responsible in their messaging, staying cognizant of their own values and biases, so as not to paradoxically harm religious constituents through shame-based rhetoric.

In sum, these findings add to the recent body of literature pointing to the integral role religion and morality play in perceptions of and attitudes about pornography (e.g., Fisher et al. 2018; Grubbs et al. 2015; Grubbs et al. 2018). They further illuminate the strong link between religiosity and support for censorship. And they fill a gap in the literature by addressing Lambe's (2004) recommendation to explore correlates of support for pornography censorship using a nationally representative sample. This is particularly valuable now given the widespread dialogue in academia, the mental health profession, and the public arena on the benefits and harms of pornography. As Hecker et al. (1995) rightly note, "Perhaps in no other area do value judgments appear as strong as in judgments about sexual issues" (p. 262).

Acknowledgements The authors thank Kort Prince for helpful feedback on the methods and analysis sections of this article.

Funding The authors declare no funding was received for this research.

\section{Compliance with Ethical Standards}

Conflict of interest The authors declare they have no conflicts of interest.

Ethical Approval All procedures performed in studies involving human participants were in accordance with the ethical standards of the institutional and/or national research committee and with the 1964 Declaration of Helsinki and its later amendments or comparable ethical standards. Because this study utilized publicly 
available secondary data, formal consent was not required nor was institutional review board approval sought after.

Informed Consent For this manuscript, the authors utilized secondary data from a long-standing, publicly available, nationally representative survey, i.e., the General Social Survey. Because no original data were collected, informed consent was not sought after nor required.

\section{References}

Adorno, T. W., Frenkel-Brunswick, E., Levinson, D. J., \& Sanford, R. N. (1950). The authoritarian personality. New York: Harper.

Altemeyer, B. (1981). Right-wing authoritarianism. Winnipeg, MB: University of Manitoba Press.

Ark. H. Res. 1042 (2017). Recognizing and finding that the proliferation and accessibility of pornography has created a public health crisis leading to a broad spectrum of individual and public health impacts and societal harms, 2017 Regular Session (2017). Retrieved from http://www.arkleg.state.ar.us/ assembly/2017/2017R/Bills/HR1042.pdf.

Carnes, P. (1983). Out of the shadows: Understanding sexual addiction. Minneapolis, MN: Compcare.

Carroll, J. (2015, January 16). Fight the New Drug addresses pornography at Provo school. The Daily Herald. Retrieved from http://www.heraldextra.com.

Carroll, J. S., Padilla-Walker, L. M., Nelson, L. J., Olson, C., Barry, C. M., \& Madsen, S. D. (2008). Generation XXX: Pornography acceptance and use among emerging adults. Journal of Adolescent Research, 23, 6-30. https://doi.org/10.1177/0743558407306348.

Cattell, R. B. (1966). The scree test for the number of factors. Multivariate Behavioral Research, 1 , 245-276. https://doi.org/10.1207/s15327906mbr0102_10.

Clarkson, J., \& Kopaczewski, S. (2013). Pornography addiction and the medicalization of free speech. Journal of Communication Inquiry, 37, 128-148. https://doi.org/10.1177/0196859913482330.

Cooper, A. (1998). Sexuality and the Internet: Surfing into the new millennium. CyberPsychology \& Behavior, 1, 187-193. https://doi.org/10.1089/cpb.1998.1.187.

Cowan, G. (1992). Feminist attitudes toward pornography control. Psychology of Women Quarterly, 16, 165-177. https://doi.org/10.1111/j.1471-6402.1992.tb00247.x.

Field, A. (2013). Discovering statistics using IBM SPSS Statistics (4th ed.). Thousand Oaks, CA: Sage.

Fight the New Drug. (2017). Fight the New Drug: Change the conversation. Retrieved from http://www. fightthenewdrug.org.

Fisher, R. D., Cook, I. J., \& Shirkey, E. C. (1994). Correlates of support for censorship of sexual, sexually violent, and violent media. The Journal of Sex Research, 31, 229-240. https://doi.org/10.1080/ 00224499409551756.

Fisher, W. A., Montgomery-Graham, S., \& Kohut, T. (2018). Pornography problems due to moral incongruence. Archives of Sexual Behavior. https://doi.org/10.1007/s10508-018-1291-7.

Fla. H. Res. 157 (2018). A resolution recognizing the public health crisis created by pornography, 2018 Legislative Session (2018). Retrieved from https://www.flsenate.gov/Session/Bill/2018/157/BillText/ Filed/PDF.

Griffiths, M. D. (2012). Internet sex addiction: A review of empirical research. Addiction Research \& Theory, 20, 111-124. https://doi.org/10.3109/16066359.2011.588351.

Grubbs, J. B., Exline, J. J., Pargament, K. I., Hook, J. N., \& Carlisle, R. D. (2015). Transgression as addiction: Religiosity and moral disapproval as predictors of perceived addiction to pornography. Archives of Sexual Behavior, 44, 125-136. https://doi.org/10.1007/s10508-013-0257-z.

Grubbs, J. B., Perry, S. L., Wilt, J. A., \& Reid, R. C. (2018). Pornography problems due to moral incongruence: An integrative model with a systematic review and meta-analysis. Archives of Sexual Behavior. https://doi.org/10.1007/s10508-018-1248-x.

Gunther, A. C. (1995). Overrating the X-rating: The third-person perception and support for the censorship of pornography. Journal of Communication, 45, 27-38. https://doi.org/10.1111/j.1460-2466.1995. tb00712.x.

Guttman, L. (1954). Some necessary conditions for common-factor analysis. Psychometrika, 19, 149-161. https://doi.org/10.1007/BF02289162.

Halpern, A. L. (2011). The proposed diagnosis of Hypersexual Disorder for inclusion in DSM-5: Unnecessary and harmful. Archives of Sexual Behavior, 40, 487-488. https://doi.org/10.1007/s10508-0119727-3. 
Hecker, L. L., Trepper, T. S., Wetchler, J. L., \& Fontaine, K. L. (1995). The influence of therapist values, religiosity and gender in the initial assessment of sexual addiction by family therapists. The American Journal of Family Therapy, 23, 261-272.

Hense, R., \& Wright, C. (1992). The development of the Attitudes Toward Censorship Questionnaire. Journal of Applied Social Psychology, 22, 1666-1675. https://doi.org/10.1111/j.1559-1816.1992. tb00968.x.

Herrman, M. S., \& Bordner, D. C. (1983). Attitudes toward pornography in a Southern community. Criminology, 21, 349-374. https://doi.org/10.1111/j.1745-9125.1983.tb00266.x.

Horn, J. L. (1965). A rationale and test for the number of factors in factor analysis. Psychometrika, 30, 179-185. https://doi.org/10.1007/BF02289447.

Kafka, M. (2010). Hypersexual Disorder: A proposed diagnosis for DSM-V. Archives of Sexual Behavior, 39, 377-400. https://doi.org/10.1007/s10508-009-9574-7.

Kaiser, H. F. (1960). The application of electronic computers to factor analysis. Educational and Psychological Measurement, 20, 141-151. https://doi.org/10.1177/001316446002000116.

Kan. H. Res. 6016 (2017). A resolution recognizing that pornography is a public health hazard that leads to a broad spectrum of individual and public health impacts and societal harms, 2017-2018 Legislative Sessions (2017). Retrieved from http://www.kslegislature.org/li/b2017_18/measures/hr6016/.

Kor, A., Fogel, Y. A., Reid, R. C., \& Potenza, M. N. (2013). Should hypersexual disorder be classified as an addiction? Sexual Addiction \& Compulsivity, 20, 27-47. https://doi.org/10.1080/10720162.2013. 768132.

Kraus, S. W., Krueger, R. B., Briken, P., First, M. B., Stein, D. J., Kaplan, M. S., et al. (2018). Compulsive sexual behaviour disorder in the ICD-11. World Psychiatry, 17, 109-110. https://doi.org/10.1002/wps. 20499.

Lambe, J. L. (2004). Who wants to censor pornography and hate speech? Mass Communication \& Society, 7, 279-299. https://doi.org/10.1207/s15327825mcs0703_2.

Lefkowitz, E. S., Gillen, M. M., Shearer, C. L., \& Boone, T. L. (2004). Religiosity, sexual behaviors, and sexual attitudes during emerging adulthood. Journal of Sex Research, 41, 150-159.

Linz, D., \& Malamuth, N. (1993). Pornography. Newbury Park, CA: Sage.

Little, R. J. A. (1988). A test of missing completely at random for multivariate data with missing values. Journal of the American Statistical Association, 83, 1198-1202. https://doi.org/10.1080/01621459. 1988.10478722 .

Lottes, I., Weinberg, M., \& Weller, I. (1993). Reactions to pornography on a college campus: For or against? Sex Roles, 29, 69-89. https://doi.org/10.1007/BF00289997.

Mockabee, S. T., Monson, J. Q., \& Grant, J. T. (2001). Measuring religious commitment among Catholic and Protestants: A new approach. Journal for the Scientific Study of Religion, 4, 675-690. https://doi. org/10.1111/0021-8294.00084.

Moser, C. (2011). Hypersexual Disorder: Just more muddled thinking. Archives of Sexual Behavior, 40, 227-229. https://doi.org/10.1007/s10508-010-9690-4.

National Opinion Research Center. (2016). The general social survey. Retrieved from http://gss.norc.org.

National Science Foundation. (2007). An overview of the General Social Survey. Retrieved from https:// www.nsf.gov/pubs/2007/nsf0748/nsf0748_3.pdf.

Parker, N. H., Hodson, K., Bennion, K. M., \& Hickman, S. (2016, October 2). Op-ed: Utah students need real sex ed, not 'Fight the New Drug.' The Salt Lake Tribune. Retrieved from http://www.sltrib.com.

Perry, S. L. (2016). From bad to worse? Pornography consumption, spousal religiosity, gender, and marital quality. Sociological Forum, 31, 441-464. https://doi.org/10.1111/socf.12252.

Pollock, P. H., III. (2012). An SPSS companion in political analysis (4th ed.). Washington, DC: Sage.

Prause, N., Pfaus, J., Blaine, S., Georgiadis, J., Kieffaber, P., Janssen, E., et al. (2016, December 12). Op-ed: Anti-porn school program misrepresents science. The Salt Lake Tribune. Retrieved from http://www. sltrib.com.

Price, J., Patterson, R., Regnerus, M., \& Walley, J. (2016). How much more XXX is Generation X consuming? Evidence of changing attitudes and behaviors related to pornography since 1973. Journal of Sex Research, 53, 12-20. https://doi.org/10.1080/00224499.2014.1003773.

Rattazzi, A. M. M., Bobbio, A., \& Canova, L. (2007). A short version of the Right-Wing Authoritarianism (RWA) Scale. Personality and Individual Differences, 43, 1223-1234. https://doi.org/10.1016/j.paid. 2007.03.013.

Republican National Committee. (2017). Republican platform: Great American families, education, healthcare, and criminal justice. Retrieved from http:/www.gop.com/platform/renewing-americanvalues/.

Rojas, H., Shah, D. V., \& Faber, R. J. (1996). For the good of others: Censorship and the third-person effect. International Journal of Public Opinion Research, 8, 163-186. https://doi.org/10.1093/ijpor/8.2.163. 
S.D. S. Con. Res. 4 (2017). Recognizing and finding that pornography is a public health crisis leading to abroad spectrum of individual and public health impacts and societal harms, 2017 Regular Session (2017). Retrieved from http://sdlegislature.gov/legislative_session/bills/Bill.aspx?Bill= SCR4\&Session $=2017$.

Short, M. B., Kasper, T. E., \& Wetterneck, C. T. (2015). The relationship between religiosity and internet pornography use. Journal of Religion and Health, 54, 571-583. https://doi.org/10.1007/s10943-0149849-8.

Stack, L. (2016, April 21). Utah's war on pornography finds skeptics. The New York Times. Retrieved from http://www.nytimes.com.

Steensland, B., Park, J. Z., Regnerus, M. D., Robinson, L. D., Wilcox, W. B., \& Woodberry, R. D. (2000). The measure of American religion: Toward improving the state of the art. Social Forces, 79, 291-318. https://doi.org/10.2307/2675572.

Sümer, Z. (2015). Gender, religiosity, sexual activity, sexual knowledge, and attitudes toward controversial aspects of sexuality. Journal of Religion and Health, 54, 2033-2044. https://doi.org/10.1007/s10943014-9831-5.

Tenn. S. J. Res. 35 (2017). A resolution to recognize pornography as a public health hazard leading to a broad spectrum of individual and public health impacts and societal harms, 2017 General Assembly (2017). Retrieved from http://www.capitol.tn.gov/Bills/110/Bill/SJR0035.pdf.

Thompson, M. E., Chaffee, S. H., \& Oshagan, H. H. (1990). Regulating pornography: A public dilemma. Journal of Communication, 40, 73-83. https://doi.org/10.1111/j.1460-2466.1990.tb02271.x.

Utah S. Con. Res. 9 (2016). Concurrent resolution on the public health crisis, 2016 General Session (2016). Retrieved from https://le.utah.gov/ 2016/bills/static/scr009.html.

Va. H. J. Res. 549 (2017). Recognizing pornography as a public health hazard leading to a broad spectrum of individual and public health impacts and societal harms, 2017 Regular Session (2017). Retrieved from https://lis.virginia.gov/cgi-bin/legp604.exe?171+ful+HJ549.

Velicer, W. F. (1976). Determining the number of components from the matrix of partial correlations. Psychometrika, 41, 321-327. https://doi.org/10.1007/BF02293557.

Wakefield, J. C. (2012). The DSM-5's proposed new categories of sexual disorder: The problem of false positives in sexual diagnosis. Clinical Social Work Journal, 40, 213-223. https://doi.org/10.1007/ s10615-011-0353-2.

Wright, P. J. (2013). U.S. males and pornography, 1973-2010: Consumption, predictors, correlates. Journal of Sex Research, 50, 60-71. https://doi.org/10.1080/00224499.2011.628132.

Zhao, X., \& Cai, X. (2008). From self-enhancement to supporting censorship: The third-person effect process in the case of Internet pornography. Mass Communication and Society, 11, 437-462. https:// doi.org/10.1080/15205430802071258.

Zouves, N. (2015, October 15). 'Fight the New Drug' anti-porn billboards pop up in Bay area. ABC 7 News. Retrieved from http://www.abc7news.com. 